\title{
CULTURA AFRO-BRASILEIRA NO ENSINO DE HISTÓRIA: UM OLHAR DOCENTE DA EDUCAÇÃO BÁSICA DE CRUZ ALTA
}

\section{AFRICAN CULTURE IN BRAZILIAN HISTORY TEACHING: A LOOK TEACHING OF BASIC EDUCATION CRUZ ALTA}

\author{
Vânia Maria Oliveira de Freitas ${ }^{1}$ \\ Aristeu Castilhos da Rocha
}

\begin{abstract}
RESUMO: O Projeto de Pesquisa intitulado História e Cultura Afro-brasileira Lei 10.639/2003: como um caminho no processo de formação docente, tem por finalidade trazer alguns apontamentos sobre a inclusão do ensino da cultura afro-brasileira no currículo do sistema educacional e sua inserção nas práticas desenvolvidas em sala de aula. Foi apresentado ao Programa Institucional de Bolsas de Iniciação Científica ${ }^{3}$ - PIBIC da Universidade de Cruz Alta e busca como objetivo central oportunizar a produção de saberes, a formação de professores e a promoção de atividades no campo das relações étnico-raciais. Analisamos questões a partir das perspectivas da atuação dos docentes em sala de aula, bem como os eventuais desafios que se colocam, nos últimos anos para os educadores ao ministrar esta disciplina no currículo escolar.
\end{abstract}

Palavras-chave: Questões raciais. Inclusão. Prática docente. Pesquisa.

\begin{abstract}
The research project titled History and Afro-Brazilian - Law 10.639/2003: as a path in the process of teaching formation, aims to bring some notes on the inclusion of the teaching of African-Brazilian culture in the curriculum of the educational system and its insertion practices developed in the classroom. It was submitted to the Institutional Program for Scientific Initiation Scholarships - PIBIC University of Cruz Alta and seeks to nurture the core objective for knowledge production, the preparation of teachers and the promotion of activities in the field of relations racial ethnical. We analyzed issues from the perspectives of the performance of teachers in the classroom, as well as any challenges in recent years for educators to teach this subject still "new" in the school curriculum.
\end{abstract}

Keywords: Racial issues. Inclusion. Teaching practice. Search.

\footnotetext{
${ }^{1}$ Professora doutora em História, pesquisadora e coordenadora do projeto História e Cultura Afrobrasileira - Lei 10.639/2003: Como um caminho no processo de formação docente. Professora Adjunta II do Centro de Ciências Humanas e Sociais e do Programa de Pós-Graduação em Práticas Socioculturais e Desenvolvimento Social da Universidade de Cruz Alta.

2 Doutor em História (PUCRS), autor do projeto de pesquisa inicial. Docente do Instituto Federal de Educação, Ciência e Tecnologia Farroupilha, Campos Júlio de Castilhos.

${ }^{3}$ Um agradecimento especial a Mariane Jardim acadêmica do curso de Jornalismo da Universidade de Cruz Alta - UNICRUZ, bolsista do projeto PIBIC.
} 


\section{Introdução}

Na atualidade, quando o mundo cada vez mais globalizado vivencia um intenso processo de mutações de ordem econômica, social, política, cultural e científica, cresce a necessidade da produção de novos saberes. De forma sintonizada com essa realidade mutante, a UNICRUZ reafirma o seu compromisso como uma instituição de inserção regional e amplia as suas possibilidades nítidas de cidadania, bem como inova a partir de novas posturas alicerçadas na tríade: Ensino, Pesquisa e Extensão.

Propõe, ainda situações interdisciplinares numa perspectiva participativa e integradora, a partir de diálogos e aproximações entre a universidade, instituições educativas, movimento negro local e regional, como marcos referenciais para a promoção de ensino, pesquisa e extensão relacionados ao campo de estudos afro-brasileiros. Pretende-se estimular uma discussão ampliada e interdisciplinar a respeito dos sentidos que se pode entender das palavras "ética" e "cidadania", aqui reconhecidas como compreensões de primeira grandeza para o especificamente humano nos plurais cenários político e educacional das sociedades contemporâneas. Ainda, é necessário mobilizar, sensibilizar e convencer os profissionais da educação no ensino superior para a reeducação do olhar sobre as contribuições próprias da história e cultura africana e afro-brasileira, as quais contribuem para o desenvolvimento de uma sociedade democrática, multicultural e pluriétnica como o Brasil.

Apresentam-se, para tanto, os seguintes propósitos: a) Conhecer a Lei 10.639/2003, bem como promover discussão, reflexão e análise do contexto histórico social da lei que foi publicada/promulgada em 2003, verificando-se seu cumprimento; produzir e relacionar tematizações concernentes aos espaços da política e da educação, no que se refere às articulações que podem compor nesses espaços entre as dimensões da ética e da cidadania, justamente nos elementos que em comum nelas se encontram; b) Discutir e divulgar os termos das justificativas que se apresentam nas pesquisas e nas convivências que se pretendem promover com eventos e com a participação de entidades e 
personalidades que possuem conhecimento em relação à História e Cultura Africana e Afro-brasileira, somando informações, dinâmicas, depoimentos e mecanismo de ação que possibilitem a compensação/reparação dos sujeitos segregados ao longo do processo histórico; c) Compreender que a sociedade é formada por pessoas que pertencem a grupos étnico-raciais distintos, que possuem cultura, história própria e igualdade, construindo em conjunto a nossa história; d) Tornar a discussão sobre as diferenças e diversidades sociais interessante do ponto de vista do aluno, possibilitando o crescimento pessoal deste indivíduo como cidadão transformador da sociedade.

Esse processo de reorganização será eficaz se contar como instituição norteadora uma escola capaz de ser um espaço social e cultural responsável pela construção qualificada do conhecimento, de formação de atitudes, posturas e valores, bem como de preservação de nosso patrimônio material e imaterial. A inserção destas temáticas nas escolas e na Universidade, como recomenda Hernandez (2005, p.11), devem suscitar "críticas, questões e debates capazes de inspirar pesquisas, multiplicando a quantidade e a qualidade de estudos sobre dilemas da contemporaneidade no continente africano".

Quando investigamos a historiografia que trata da trajetória da humanidade, percebemos a presença da etnia negra em diferentes espaços e temporalidades, mas é na África, e a partir dela, que ocorre a "Diáspora Negra"4.

O conceito negro é uma construção cultural carregada de significados e que tem suas origens ligadas à cristandade medieval e ao Iluminismo. 0 vocábulo negro designa "cor". Na América e no Brasil adquire uma conotação social discriminatória e racista ao se referir aos africanos e/ou brasileiros. Essa identificação negativa, de acordo com Silva/Silva (2005, p.313), tem a ver com a cor da pele escura que

\footnotetext{
${ }^{4}$ É o nome que se dá ao fenômeno sociocultural e histórico que ocorreu em países além África devido à imigração forçada, por fins escravagistas mercantis que perduraram da Idade Moderna ao final do século XIX, de africanos (em especial africanos de pele escura chamados pela cultura ocidental de negros ou afro-descendente).
} 
talvez se deva à dicotomia que existe na cultura ocidental entre a cor branca, que significa o bem, a beleza, a pureza, e a cor preta que representa o mal, a morte, o medo. Para o pensamento cristão, o preto era cor do demônio, atribuído a acontecimentos nefastos como a "peste negra" e a "magia negra". A cor negra tinha assim, conotação sinistra para o Ocidente, que se combinou à condição de escravos dos africanos encontrados na América e na Europa para construir um conceito pejorativo a cerca do negro como indivíduo.

Na Idade Moderna, em meio ao contexto das grandes navegações e da "Europeização do Mundo", é que a África vai ser, gradativamente, agregada às atividades mercantilistas como fonte fornecedora de matéria-prima farta, resistente, qualificada e barata. À luz do mercantilismo inaugura-se e intensificase o comércio triangular e o tráfico de origem africana com destino às áreas de plantations localizadas na América de colonização hispânica e no Brasil. Nessa perspectiva, Gomes (2003, p.448) adverte que

há pressão das economias coloniais por braços escravos e, fundamentalmente, o negócio lucrativo do tráfico atlântico africano que envolvia, além de comerciantes europeus, as elites coloniais aliás, foram estas as que mais lucraram com o tráfico e constituíram sobre a escravidão negra suas riquezas. Assim, cada vez mais homens e mulheres africanos escravizados desembarcavam nas áreas coloniais. Calcula-se em dez milhões, ou mais, a quantidade de africanos transportados para as várias regiões das Américas entre os séculos XVI e XIX, tendo o Brasil recebido $40 \%$ destes.

A nossa dinâmica inicial vem da Península Ibéria. A África entra em um segundo momento, quando diferentes grupos étnicos oriundos, principalmente do Congo, Angola, Benin e Gana começaram a desembarcar no Sudeste e Nordeste. Ao longo dessa experiência histórica foram se localizando, de forma acentuada, nos atuais estados de Minas Gerais, Rio de Janeiro, Bahia, Pernambuco e Maranhão. Os mesmos passaram a constituir "braços" para as lavouras ou extração de riquezas naturais tornando-se, capital dos grandes proprietários e dando origem às elites regionais. Os escravos trazidos nos navios negreiros não eram apenas mercadorias que atendiam as exigências 
mercantilistas. Rocha e Camargo (2011, p.114) afirmam entre eles vinham "reis, guerreiros, sábios, músicos, artistas, pensadores e estrategistas".

O conceito de negro enquanto construção cultural insere-se na trajetória histórica dos povos marcados pelas diferenças culturais. Nessa perspectiva a abordagem do conceito de negro articula-se, principalmente a partir da década de 1980, ao conceito de multiculturalismo. Nos últimos tempos o mesmo avança e aponta a interdisciplinaridade como caminho para as discussões da pluralidade cultural. Na realidade segundo Ribeiro e Oliveira (2011, p.102) estuda e faz a crítica ao etnocentrismo, aos estereótipos, buscando espaços para a incorporação de uma pluralidade de vozes, de diversas formas de se construir e interpretar a realidade e, tentando reconstruir histórias que produzem identidades plurais, procura desconstruir discursos hegemônicos que se pretendem universais.

Os negros contribuíram, de forma significativa, na formação histórica e cultural do Brasil. É notável a sua participação como força de trabalho em todas as atividades complementares que subsidiaram momentos de evolução econômica nacional. O processo exploratório dos africanos, enquanto escravos, não foi pacífico. Ao contrário, foi marcado pela luta e opressão. Os negros resistiram através de assassinatos, abortos, suicídios, dançando a capoeira e refugiando-se nos quilombos como o de Palmares, sob a liderança de um estrategista conhecido como Zumbi.

Observa-se, ainda, que a religiosidade constituiu-se em um dos amparos para que os negros resistissem à escravidão. À noite, quando eles rufavam os tambores e enalteciam os orixás, ficavam mais fortes para enfrentar as adversidades do dia seguinte ou mesmo para fugir na escuridão. Além da epopeia de Palmares, é interessante lembrar a participação dos negros na Conjuração Baiana (1798), Revolta dos Malês (1835), na Revolução Farroupilha (1835/1845), na Guerra do Paraguai (1865/1870) ...

No processo de composição étnica é notável a participação africana na formação da nossa matriz antropológica, nas manifestações sociais, culturais e religiosas. As mesmas não se limitam apenas ao futebol, à capoeira e ao carnaval. É plena a contribuição africana na religiosidade, literatura, teatro, 
cinema e educação. Cabe dizer, de acordo com Quevedo (2010), que a "escravidão não impediu aos afro-brasileiros de promoverem a continuidade de suas histórias, memórias, culturas e visões de mundo".

No plano externo, as pressões contra o tráfico negreiro e ao trabalho escravo estão intimamente ligadas aos interesses da expansão do capitalismo industrial inglês. Em 1815 a corte portuguesa, no Brasil, havia concordado em restringir o tráfico ao sul do Equador. A Inglaterra, por questões econômicas, posiciona-se contra a continuidade do tráfico, fazendo com que o parlamento brasileiro acorde não apenas a restrição, mas a proibição, através da Lei Eusébio de Queiroz (1850).

Além das influências externas, no plano interno a Campanha Abolicionista ganha o apoio de intelectuais como Castro Alves, Joaquim Nabuco e José do Patrocínio. Dessa forma, ocorre a emancipação lenta e gradual a partir das chamadas "Leis para inglês ver" ${ }^{15}$ : Lei do Ventre Livre (1871), Lei do Sexagenário ou Saraiva Cotegipe (1875) e a Lei Áurea (1888), esta determina a extinção da escravidão no Brasil.

$\mathrm{Na}$ realidade, esse processo foi parcial, o negro não estava preparado para ser livre e a sociedade não the ofereceu as condições necessárias para tal. Começa a migração desumana dos negros das senzalas para as favelas, e seus reflexos podem ser observados até hoje através de uma nítida ausência de justiça social em que vive ou sobrevive essa grande parcela da população brasileira. Ao investigar o contexto após a abolição da escravidão, Mattos (2007, p.217) enfatiza que os africanos e seus descendentes tiveram de enfrentar o difícil acesso ao mercado de trabalho livre, a discriminação e a exclusão racial.

Ao revisitarmos a História da Educação Brasileira percebemos silêncios a respeito da participação do negro enquanto sujeito do processo educativo. Do período colonial até o início da Era Vargas a escola constituía-se como uma instituição excludente. As crianças e jovens oriundos das camadas populares, ou seja, índios, negros e pobres foram alijados das atividades socioeducativas. Esse

\footnotetext{
${ }^{5}$ Leis para inglês ver é a expressão usada no Brasil para leis consideradas demagógicas e que não
} são cumpridas na prática. 
panorama começa a ser modificado com a implementação das políticas educacionais da Era Vargas (1930-1945).

Nos currículos escolares do período colonial os conteúdos de História, praticamente, inexistem. Os únicos contatos dos alunos com a História ocorriam quando era feita a leitura de textos de autores greco-latinos. Com a criação da disciplina de História no Imperial Colégio D. Pedro II (1837), no Rio de Janeiro, a situação pouco se modifica, pois o ensino de História ocorre sob a ótica do eurocentrismo. $O$ índio é tratado como algo folclórico e o negro como mercadoria ou mão de obra escrava.

A História e a resistência do povo negro no processo histórico ocorrem em meio à continuidade e descontinuidade vivenciadas de forma individual e coletiva, nas senzalas, nas comunidades quilombolas, nos terreiros, nas irmandades religiosas e mais recentemente nas Escolas de Samba, Grupos Culturais e no Movimento Negro. Na realidade, trata-se de uma luta contra as ideologias, as desigualdades e os estereótipos racistas, por melhores condições sociais, saúde e trabalho, pelo acesso à permanência, a uma educação de qualidade para as crianças e jovens afrodescendentes.

A temática relativa à História e Cultura da África e dos Afro-brasileiros, ausente dos currículos até então, é proposta pela Lei 9394/1996 mas torna-se obrigatória em todos os níveis de ensino através da Lei $10.639 / 2003$. Essa obrigatoriedade lança um enorme desafio para as escolas e para os programas de formação de professores. A sua inserção nos currículos vem ao encontro do pensamento de Serrano e Waldman (2007, p.13) no sentido de buscar "desse modo contribuir com a ampliação do exercício da cidadania e do fortalecimento de laços identitários nacionais".

Em um contexto marcado por problemas de ordem econômica, política e social é urgente a intervenção do Estado em prol da igualdade, justiça e inclusão social. O encaminhamento dessas questões passa pelo entendimento da Educação como direito social e caminho seguro para o desenvolvimento humano.

É interessante observar que as ações afirmativas precisam ser implementadas nas instâncias da Universidade como tomada de posições para a 
produção e socialização de saberes relativos à História e a Cultura da África e Afro-brasileira, questionamento das relações étnico-raciais, valorização da diversidade, criação de estratégias e práticas pedagógicas inovadoras nos programas de formação inicial e continuada de professores. Nesse sentido, recorremos à Oerer (2010, p.123) quando exige:

a Resolução CNE/CP 1/2004 deve ser referendada nos cursos de formação dos profissionais (Pedagogia, Licenciaturas em História e Geografia, Filosofia, Letras, Química, Física, Matemática, Biologia, Psicologia, Sociologia/Ciências Sociais, Artes e as correlacionadas), assim como Curso Normal Superior, tanto nas atividades acadêmicas (disciplinas, módulos, seminários, estágios) comuns a todos eles, quanto nas específicas, possibilitando aprofundamentos e o tratamento de temáticas voltadas à especificidade de cada área de conhecimento.

De modo sucinto, empreendemos breves reflexões sobre História e a Cultura da África e dos Afro-brasileiros, bem como a sua inserção nas atividades da escola básica e na Universidade. A ideia teve como proposta contribuir no processo de formação docente. Por fim, pensamos em estabelecer relações entre ensino, pesquisa e extensão a partir do desenvolvimento de ações de natureza inclusiva, cooperativa, interdisciplinar, democrática e de cidadania. Este referencial foi o ponto de partida para a construção das bases teóricas que apontaram os caminhos para a dinamização do projeto.

\section{Metodologia}

O projeto desenvolveu-se a partir de atividades de caráter qualitativo como: investigação bibliográfica, discussões teóricas, organização e aplicação de questionários.

Segundo Oliveira (2002, p.61), as abordagens qualitativas facilitam descrever problemas, bem como analisar, compreender e classificar 
determinados processos sociais, oferecer contribuições no processo das mudanças, criação ou formação de opiniões de determinados grupos.

Nos propomos a realizar um projeto de pesquisa que abordasse a História e Cultura Afro-brasileira no Contexto Escolar, a fim de construir uma referência à multiculturalidade nas escolas de atuação dos professores entrevistados. Nessa perspectiva, analisamos os dados coletados para a realização deste artigo, cujo objetivo da pesquisa é verificar o entendimento dos professores e diagnosticar a realidade da inserção da temática no currículo da Educação Básica.

Visitamos dez escolas de Ensino Médio e Fundamental, onde foram aplicados os questionários aos professores que trabalham com a temática. Duas delas são municipais, duas particulares e seis estaduais. As escolas são as seguintes: Escola Estadual de Ensino Fundamental Dr. Gabriel Álvaro de Miranda, Escola Estadual de Ensino Médio Major Belarmino Cortês, Escola Estadual de Ensino Fundamental Dr. Catharino de Azambuja, Escola Estadual de Ensino Fundamental Dr. Cândido Machado, Escola Estadual de Ensino Médio Maria Bandarra Westphalen, Escola Estadual de Ensino Fundamental Pacífico Dias da Fonseca, Escola Municipal de Ensino Fundamental Carlos Gomes, Escola Municipal de Ensino Fundamental Gabriel Annes da Silva, FACCENTRO, Escola CooperAção.

Cabe ressaltar que a abordagem qualitativa foi utilizada para caracterizar o contexto do estudo, que visava dar maior precisão aos dados coletados que posteriormente foram analisados. No entanto, segundo Demo (2001) apud Queiroz (2006, p.9), a abordagem qualitativa

... deve observar tudo o que é ou não falado, pois muitas vezes os gestos, o balançar da cabeça, a expressão corporal e facial dos informantes, o vaivém das mãos e tudo o que ocorre no campo durante uma pesquisa pode estar imbuído de sentido e expressão.

Este estudo também consiste em uma pesquisa descritivo-interpretativa. De acordo com Triviños (1987), a pesquisa qualitativa é descritiva quando a qualidade dos seus resultados é expressa. Além disso, a compreensão ampla de 
um fenômeno exige que se considerem, inicialmente pelo menos, todos os dados da realidade como importantes, expressos em "retratos (ou descrições), em narrativas, ilustradas com declarações das pessoas para dar o fundamento concreto necessário como fotografias, etc., acompanhados de documentos pessoais, fragmentos de entrevistas, etc.". E, por isso, passíveis de exame, afirma Triviños (1987, p.128).

Através da aplicação do questionário obtivemos um diagnóstico sobre a realidade da inserção das práticas pedagógicas implementadas e em desenvolvimento para atender a obrigatoriedade do estudo da história e cultura afro-brasileira no âmbito do currículo da Educação Básica nas escolas de Cruz Alta. Para tanto, foi investigada a legislação correlata ao estudo da história e cultura afro-brasileira, ações educativas que (re) signifiquem as práticas pedagógicas no currículo escolar, a fim de compreender como integramos um mosaico cultural.

Podem-se criar histórias, trabalhar com a imaginação, escrever, ler, tocar um instrumento, desenhar... Enfim, reconhecer e identificar as práticas, representações, expressões, buscando estratégias para o entendimento dos aspectos históricos da Cultura Afro-brasileira de maneira coletiva.

Dialogamos com o projeto em três campos que julgamos necessários para uma melhor compreensão do multiculturalismo. No campo educacional: contextualização e compreensão da produção da diferença (tem como experiência a discriminação e o preconceito no interior da sociedade em que vivem; grupos culturalmente dominados; engajamento nas lutas; busca de modificação através das ações, da lógica pela qual a sociedade produz sentidos e significados de si mesma). As abordagens do campo educacional estão colocadas aos propósitos e esforços de cunho político.

No campo político: ressignificação dos conceitos como direitos humanos, democracia, cidadania... Articula as reivindicações identitárias, garantia de representação política, questionamento às injustiças, desrespeito às especialidades dos grupos, desconstrução dos discursos, efetivação da representatividade das identidades plurais, busca de oportunidades iguais. 
No campo teórico: questiona o conhecimento transmitido, produz e mantêm as culturas, etnocentrismo, estereótipos, busca abertura para incorporação da pluralidade de vozes, das diversas formas de construir e interpretar a realidade. Permite uma leitura de mundo a partir de procedimentos lógicos inerentes às culturas dominadas, produzindo um novo conhecimento, uma nova subjetividade descentrada e emancipada de valores supostamente superiores, recuperação de histórias e visões de mundo que perfazem as identidades plurais, buscando subverter a lógica dos discursos culturais hegemônicos e as narrativas mestras que se pretendem universais.

Em síntese, o projeto de pesquisa não poderia ter um título mais apropriado para nos mostrar a necessidade de evitar a cisão da didática para que pudéssemos avaliar as condições do multiculturalismo na História e Cultura AfroBrasileira no contexto escolar, na resolução cooperativa dos problemas com adaptações e estratégias. Para nós, o que ficou como lição deste projeto no papel de pesquisadores foi o contínuo resgate da competência pedagógica e dos professores com confiança em vencer desafios superando obstáculos, sempre.

\section{Resultados}

Em relação aos questionamentos realizados aos professores, percebemos uma série de críticas no que envolve o ensino dessa temática no currículo escolar, como conteúdo a desenvolver. Dentre os principais itens destacados, a discussão gira em torno da obrigatoriedade do ensino da História e Cultura Afrobrasileira. Ensinar História e Cultura Afro-brasileira e africana não é mais uma questão de vontade pessoal e de interesse particular, é uma questão curricular de caráter obrigatório que envolve as diferentes comunidades: escolar, familiar e sociedade. Entretanto, os professores, que em sua formação também não receberam preparo especial para o ensino da referida cultura e suas reais influências para a formação da identidade do nosso país, entram em conflito quanto a melhor maneira de trabalhar essa temática na escola. 
Para esta análise, não vamos utilizar os nomes reais dos professores para que não haja exposição de sua imagem. Citaremos quatro falas de professores, nas quais serão denominados de professores 1 a 4. Com relação à abordagem que se deve fazer em sala de aula, o que se percebe é que a maioria desconhece a intenção da lei, conforme podemos observar em uma das respostas da professora 1: "O tema é extremamente relevante, entretanto, não vejo a necessidade da criação de uma lei para obrigar a trabalhar ele, pois sempre abordei o assunto ao longo dos conteúdos".

Percebemos também, que alguns professores não tiveram o devido aprofundamento sobre o tema durante o estudo na faculdade, como cita a professora 2: "Penso que quando fizemos (quando eu fiz faculdade) aprofundouse muito pouco sobre esse tema. E se não fosse a gente pesquisar em livros e internet não teríamos a informação necessária para trabalharmos com os educandos. É de muita importância que se trabalhe esse tema na escola".

Para ressignificar a prática docente percebe-se a necessidade de uma estratégia do descobrimento pela via da participação coletiva, entendendo os aspectos históricos, fazendo com que os educandos tornem-se multiplicadores do conhecimento adquirido nas atividades.

De acordo com Secad (2006, p.239)

... daí a necessidade de se investir para que os professores (...) recebam formação que os capacite não só a compreender a importância das questões relacionadas à diversidade étnico-racial, mas a lidar positivamente com pedagogias que possam auxiliar a reeducá-las.

Trabalhar a desigualdade social faz emergir um grande desafio constante por parte dos educadores, uma busca contínua de alternativas que visem a quebrar certos paradigmas.

Segundo os Parâmetros Curriculares Nacionais (1997, p.19):

A temática da Pluralidade Cultural diz respeito ao conhecimento e a valorização das características étnicas e culturais dos diferentes grupos sociais, que convivem no território nacional, às 
desigualdades socioeconômicas e a crítica às relações sociais discriminatórias e excludentes que permeiam a sociedade brasileira, oferecendo ao aluno a possibilidade de conhecer o Brasil como um país complexo, multifacetado e algumas vezes paradoxal.

O multiculturalismo é o reconhecimento da pluralidade de culturas, etnias, religiões, visões de mundo, podemos listar neste projeto de pesquisa, que nas falas dos professores fica visível algumas questões que extrapolam o âmbito escolar, estão presentes no cotidiano, no desprezo ao outro por vários motivos como: diversidade cultural, realidades diferentes, formas de vida, visão de mundo, conhecimento, processos relacionais, relações de poder.

Percebemos a necessidade desses profissionais de educação pensar formas de valorizar e incorporar em políticas e práticas curriculares, refletindo sobre mecanismos de discriminação como forma de silenciar essas pluralidades culturais na sociedade, negando voz, impondo a homogeneização/visão monocultural, negando os conflitos culturais dos diferentes grupos sociais.

Segundo a fala da professora 3: "Na minha opinião a Lei 10.639 veio para fortalecer assegurando o direito a igualdade de condição de cidadania, garantindo o acesso às fontes históricas e culturais do Brasil, pois nosso povo precisa saber e reconhecer o negro como um herói".

A condição de existência do multiculturalismo é a presença do diálogo, situando a emergência do tema, clarificando abordagens teóricas e desdobramentos curriculares, trabalhando tensões e detectando potenciais de uma abordagem multicultural na promoção de uma educação democratizada, crítica e pautada na sensibilização à necessidade participativa.

Também analisamos outros aspectos ao interagir com o projeto: como uma visão do iluminismo em que a cultura é o processo de desenvolvimento social atrelado ao desenvolvimento da sociedade europeia, na antropologia especialmente no dizer de Laraia (2005) e Gomes (2011) em que a cultura são os diferentes modos de vida, valores, significações, espaço/tempo histórico compartilhado por grupos, na linguagem em que a cultura é 
fazer/práticas/significações/trocas/interrelações/movimento/produções/criação trabalho.

$\mathrm{Na}$ opinião da professora 4: "Primeiro não posso aceitar que se coloque algo obrigatório. O tema é importante para a questão do resgate histórico da cultura afro, mas penso que temos hoje na escola muitos temas a serem abordados e tudo cai nas áreas humanas. Então em alguns anos damos prioridades a outros temas".

Porém, trabalhar essas questões provoca um grande desafio por parte dos educadores, numa busca contínua de soluções que possibilitem a formação de cidadãos conscientes, sem traços de preconceitos e assim possam constituir uma sociedade mais justa e igualitária.

Sabe-se, que a escola enquanto espaço social deve fomentar a integração dos educandos com as questões culturais e raciais, muitas vezes não contempladas no currículo e nem mesmo mencionadas em seus Projetos PolíticoPedagógicos. Assim, com a implantação da Lei 10.639/200 buscou-se um maior reconhecimento do povo africano, que ao longo dos anos muito contribuiu e contribuem para o desenvolvimento do nosso país. Também, acima de tudo, procurou-se despertar o interesse nas crianças desde a educação infantil, em conhecer e a respeitar as diferenças raciais, desenvolvendo o senso crítico e garantindo igualdade de oportunidades para todos. Ainda, defender que a educação sempre foi tratada como instrumento de grande valia para a promoção de demandas da população negra, com o dever de combater as desigualdades sociais e raciais.

Cabe ressaltar que o projeto teve como proposta encorajar seus integrantes e demais a voltarem sua atenção para estas temáticas. $O$ projeto inova ao procurar sensibilizar acadêmicos, docentes e sociedade para a valorização da História Cultural e Patrimônio Afro-brasileiro ao assumir a promoção da equidade e diversidade na UNICRUZ no âmbito local e regional. 


\section{Considerações finais}

Ao concluir esta pesquisa, queremos enfatizar que realizar uma prática pedagógica com empenho e dedicação, torna o trabalho muito mais produtivo. Com os professores, deve haver a conscientização de que essa missão de educador é nobre, dependendo deles a inclusão de todos os educandos, independente de raça ou credo.

Este estudo foi de fundamental importância, nos levando a perceber que cabe aos educadores uma grande responsabilidade social, pois educar pela diversidade cultural e étnica vai além de falar aos alunos que todos somos iguais perante a lei e que existem culturas diferentes.

A Lei 10.639 é consequência de uma luta dos negros por uma educação que considere a diversidade. Não existe fórmula, é necessário construir uma proposta de aplicação. O desafio está em criar, pesquisar, inventar meios para que no futuro tenhamos uma sociedade com mais respeito e igualdade. $A$ educação, a cada dia que passa, tem um papel importante na construção da identidade do afro-brasileiro. Assim, se torna necessário a escola criar relações diferentes para que os educandos se sintam incluídos. A religião, as danças, as músicas, as histórias e lendas afro-brasileiras podem oferecer subsídios para um trabalho muito rico em sala de aula, devido à diversidade de elementos que apresentam.

É preciso pensar na escola como uma instituição que pode contribuir para a transformação social. No entanto, também não podemos acreditar pura e simplesmente que a escola pode tudo transformar.

Para concluir, segundo Rocha, (2012 p.6) "O ensino de História cresce à medida que vivenciamos novas práticas culturais e pedagógicas. No linear do contemporâneo fomos desafiados a implementar novas ações as quais, de certa forma, nos remetem como diz Milton Nascimento para os "trilhos da nossa história". A Educação e o Ensino de História necessitam, com urgência, partir do pensamento único, restrito e definitivo para uma realidade plural, abrangente, e 
em permanente (re)construção. Esse é o ímpeto que deve conduzir as nossas iniciativas em prol de uma educação condizente às necessidades do século XXI".

\section{Referências}

BRASIL. Orientações e Ações para Educação das Relações Étnico-raciais. Brasília: MEC/SECAD, 2010.

. Parâmetros Curriculares Nacionais. Secretaria de Educação

Fundamental. Brasília: MEC/SEF, 1997.

.Secretaria da Educação Continuada, Alfabetização, Diversidade e Inclusão. Brasília: MEC /SECAD, 2006.

GOMES, F. dos S. Sonhando com a terra, construindo a cidadania. In: PINSKY, J.; PINSKY, C. B. (Org.). História da Cidadania. São Paulo: Contexto, 2003, p.447-467.

GOMES, M. P. Antropologia. São Paulo: Contexto, 2011.

HERNANDEZ, L. L. A África na sala de aula. Visita à História Contemporânea. São Paulo: Selo Negro, 2005.

LARAIA, R. de B. Cultura: um conceito antropológico. Rio de Janeiro: Jorge Zahar, 2005.

MATTOS, R. A. História e Cultura afro-brasileira. São Paulo: Contexto/UNESCO, 2007.

OLIVEIRA, S. L. de. Metodologia Científica Aplicada ao Direito. São Paulo:

Thomson, 2002.

QUEIROZ, L. R. S. Pesquisa quantitativa e pesquisa qualitativa: Perspectivas para o campo da etnomusicologia. Claves. n. 2, p.87-98. 2006.

QUEVEDO, J. História e Cultura: Contexto Lei 10.639/03. Palestra realizada na VI Semana da Consciência Negra. Cruz Alta: UNICRUZ, 16 a 19/11/2010.

ROCHA, A. C. da; CAMARGO, M. A. S.. A História da África e da Cultura afrobrasileira no cotidiano educacional: reflexões sobre um legado histórico-cultural. In: SOUZA, A. E. (Org.). Educação, Sociedade e Cultura: reflexões interdisciplinares. Curitiba: CRV. p.113 - 123. 2011.

. Desafios para o ensino de História e Cultura Afro-Brasileira e Indígena. Jornada Nacional da Educação Santa Maria: Unifra. p.01-09.

RIBEIRO, C. M. C.; OLIVEIRA, L. FI de. Uma outra lógica é possível? Linguagem matemática e culturas Africanas nos anos iniciais. In: FERRAZ, M. C. de Oliveira 
Reis et al (Org.). Escola, Culturas e Diferenças: Experiências e desafios na Educação Básica. Rio de Janeiro: Imperial Novo Milênio, 2011. p. 89-108

SERRANO, C.; WALDMAN, M. Memória D'África. A temática africana em sala de aula. São Paulo: Cortez, 2007.

SILVA, K. V.; SILVA, H. M. Dicionário de conceitos históricos. São Paulo: Contexto, 2005.

TRIVIÑOS, A. N. S. Introdução à Pesquisa em Ciências Sociais: a pesquisa qualitativa em educação: o positivismo, a fenomenologia e marxismo. Volume Único. São Paulo: Atlas, 1987.

Recebido em 06 de Outubro de 2013.

Aprovado em 03 de Março de 2015. 